\title{
Mobile Money - A Potential Threat to Banks?
}

\author{
Kumangkem Kennedy Kubuga \\ Tamale Polytechnic, \\ Ghana
}

\author{
J. Kok Konjaang \\ Bolgatanga Polytechnic, \\ Ghana
}

\begin{abstract}
Money, the medium of exchange has seen significant transformation over centuries. In the last few hundred years, money has been regulated by banks. Such regulation of the flow of money in itself has become a money making venture becoming the main stay of several kinds of institutions including banking institutions.

The paper focuses on the emerging trend of the use of mobile devices to facilitate the payment of goods and services. This is essentially, using a mobile phone to perform some of the duties of traditional banks. This fast paced substitution of the mobile phone with traditional banking is sometimes viewed as a threat to the existence of banks in Ghana.

The paper finds, through the use of empirical data and interviews, that although, banks may lose minimally in the short term, mobile money is actually more complementary and will only fast track the achievement of the goal of a cashless economy.
\end{abstract}

\section{Keywords}

TAM, ATU, BIU,

\section{INTRODUCTION}

One of the reasons for the success of our species is the ability to exchange ideas and resources. Resources are often shared in a bidirectional manner. Even before modern conventional media of exchange such as money came into use over 3 millennia ago, barter trade facilitated the exchange of goods and services [1]. It motivated parties to continuously give out important resources in exchange of more urgent ones. With the attendant disadvantages, different tools have been adapted to facilitate the exchange of resources in the form of goods and services. In different cultures and at different times, cowry shells, minted coins and beads effectively played the roles of appropriate media for the exchange of goods and services. Paper money is thought to have come in existence in 11th Century China in the Song Dynasty [2]. It would later be introduced to Europe and the rest of the world from the 13th century [3]. In pre-colonial Ghana, the media of exchange were mainly cowries and gold dust depending on the market location. After 1844, the British West African pound was the official medium of exchange till after independence in 1957. Even so, cowries and gold dust were used in parallel with paper money well into the 20th century [4]. This led to the rise of banking with Ghana's first indigenous bank in 1950 [5]. Since independence in 1957, the cedi became the medium of exchange, borrowing the name from a local name for cowry, 'sidie'. A cedi is the equivalent of a 100 pesewas, a name also borrowed from a standard measure of gold used in precolonial times as a currency, 'mpesuwa'.

Ghana would move with the rest of the world to the use of electronic systems in the exchange of money and in making payments in the later part of the 20th century with the use of ATM machines, electronic cards and electronic money. The first ATM in Ghana was installed in 1995 [6].
In recent times, with the spread of mobile phones, there is an increasing tendency for the exchange of money and the use of mobile phones to converge. The paper studies the phenomenon and enquires whether or not mobile money would become a competitor to traditional banking.

Mobile telephony was introduced into Ghana in 1992 and after over a decade of slow growth, reforms and liberalization, the sector saw a surge in the number of mobile telephone subscribers growing through a mobile teledensity of 0.005 in 2000 , with a total (fixed and mobile) teledensity of $0.02 \%$ [7] $52.4 \%$ with mobile phones accounting for $99 \%$ of teledensity at year end 2008 [8]. As at February 2016, the mobile teledensity alone stood at $130 \%$ [9].

Today there is a ubiquity of mobile telephone coverage and mobile telecom agents who sell airtime, perform basic SIM card troubleshooting and become a first line help desk for the telecom providers. They are especially useful in rural and remote areas.

\subsection{Mobile Money}

Mobile money, simultaneously referred to as mobile payment, mobile money transfer and mobile wallet generally refer to payment services operated under financial regulation and performed from or via a mobile device. [10]. For mobile SIM card users, mobile money services are accessible at any of several thousands of mobile money agents nationwide with a valid national ID card. Upon activation of the service on the SIM card, users are able to deposit (cash in) and withdraw (cash out) as desired at an agent's. Mobile money users are also able to send money directly from their phones to other mobile money users.

With the rapid growth and near ubiquity of Mobile Networks and very low penetration of banking in the country, it has always just been a matter of time before the ubiquitous telecom sector and the omnipresent medium of exchange, money, get a convergence point - mobile money. Mobile money services were first introduced in Ghana in 2009 by the leading mobile telecom provider, MTN. The other telecommunication networks, Airtel, Vodafone and Tigo have since joined the mobile money service market, fiercely competing with the pioneer.

Today, Mobile Money is almost as ubiquitous as the Ghana cedi. In contrast, banks are not as widespread as the money they regulate.

Since 2009, when the first mobile money client was served, there has been significant progress in the sector. With a total client base of over 35 million clients, $17 \%$ of them have active mobile money accounts. The number of mobile money users, however, has been growing rapidly doubling from the previous year to the current $17 \%$ [11] with the value of transactions seeing an astronomical jump growth of $483 \%$ from GHC2.4billion as at 2013 to about GHC11.6billion in 2014, according to Bank of Ghana. In comparison, according to the Central Bank, banking operations are heavily urban- 
based and highly concentrated in the southern part of the country with unbanked population ratio of over 80 percent. As examples, on the $57 \mathrm{~km}$ research journey from Walewale to Nalerigu, only one bank was observed.

\section{THEORETICAL FRAMEWORK TECHNOLOGY ACCEPTANCE MODEL (TAM)}

As the research sought to explain and possibly predict user behaviour with respect to adoption and acceptance patterns of new technologies and innovations (mobile money in this case), the Technology Acceptance Model (TAM) [12] was employed for the research. It may be argued that mobile money is not purely a (new) technology and thus not suited for the TAM. Fortunately, previous studies on Value Added [Mobile] Services by [13] proved that the theory is applicable to such services too. Even earlier work had already begun to validate the theory also using Value Added Services [14]; [15].

The research therefore sought to examine mobile network subscribers' usage of the mobile money service utilising the Technology Acceptance Model (TAM): what are individual user's Perceptions of Usefulness (PU), Ease of Use (PEOU) and Attitude towards Usage (ATU) of the service that inform their Behavioural Intention to Use (BIU) the system?

Specifically, the research tries to better understand how these factors support technology acceptance in the context of mobile money. It necessitated a thorough reading of the TAM to support in the effort to analyse any possible reasons for resistance or acceptance toward the service and would further enable the recommendation of efficient measures to improve user acceptance/usage of the service.

The model is built on the understanding that three things; Attitudes Towards Usage (ATU), Perceived Usefulness (PU) and Perceived Ease of Use (PEOU) are crucial determinants of system (or service) adoption and use [12]. A positive ATU lays a favorable foundation or intention toward using the service that consequently affects its use. Perceived Usefulness (PU) is the degree to which a person believes that using a service will enhance his or her performance and Perceived Ease of Use (PEOU) is "the degree to which a person believes that using a particular system will be free of effort" [12].

In using the TAM therefore, the research concentrates on the following assumptions;
- If mobile money users perceive the service as useful and easy to use, they are likely to have a more positive attitude towards using it

- If mobile money users have a positive attitude towards the service, they may use the service more frequently. The assumptions are illustrated in Figure 1.

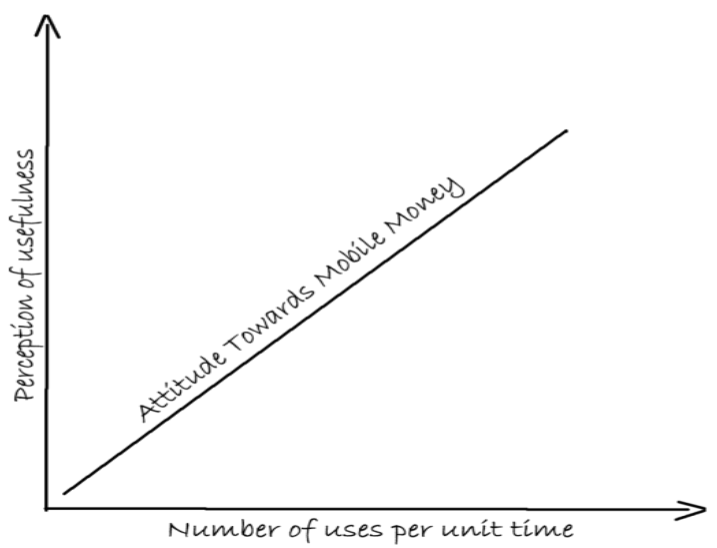

Figure 1: Factors that influence user attitude towards mobile money

\section{METHODOLOGY}

To ensure an increased credibility and validity of the results, the research used triangulation as one of the techniques. Erina's work on methodologies [16], asserts that such an approach supports to crosscheck information to produce accurate results for certainty in data collection. Data used in this paper derives from a study conducted in the first half of 2016 using a mixed method approach. The research made use of survey questionnaire, interviews; structured and unstructured and focus group discussions. The results of the survey which are the main source of data for this paper involved one hundred and thirty one randomly selected mobile money users from 8 communities in 7 districts in three of the ten regions of Ghana; Upper East, Upper West and Northern Regions. Respondents were selected at random by 12 mobile money agents who volunteered to be trained as enumerators for the research. They randomly gave questionnaire to clients of their mobile money services while attempting to balance the gender and age distribution of respondents. Figure 2 shows the locations in Ghana where the research collected data. 


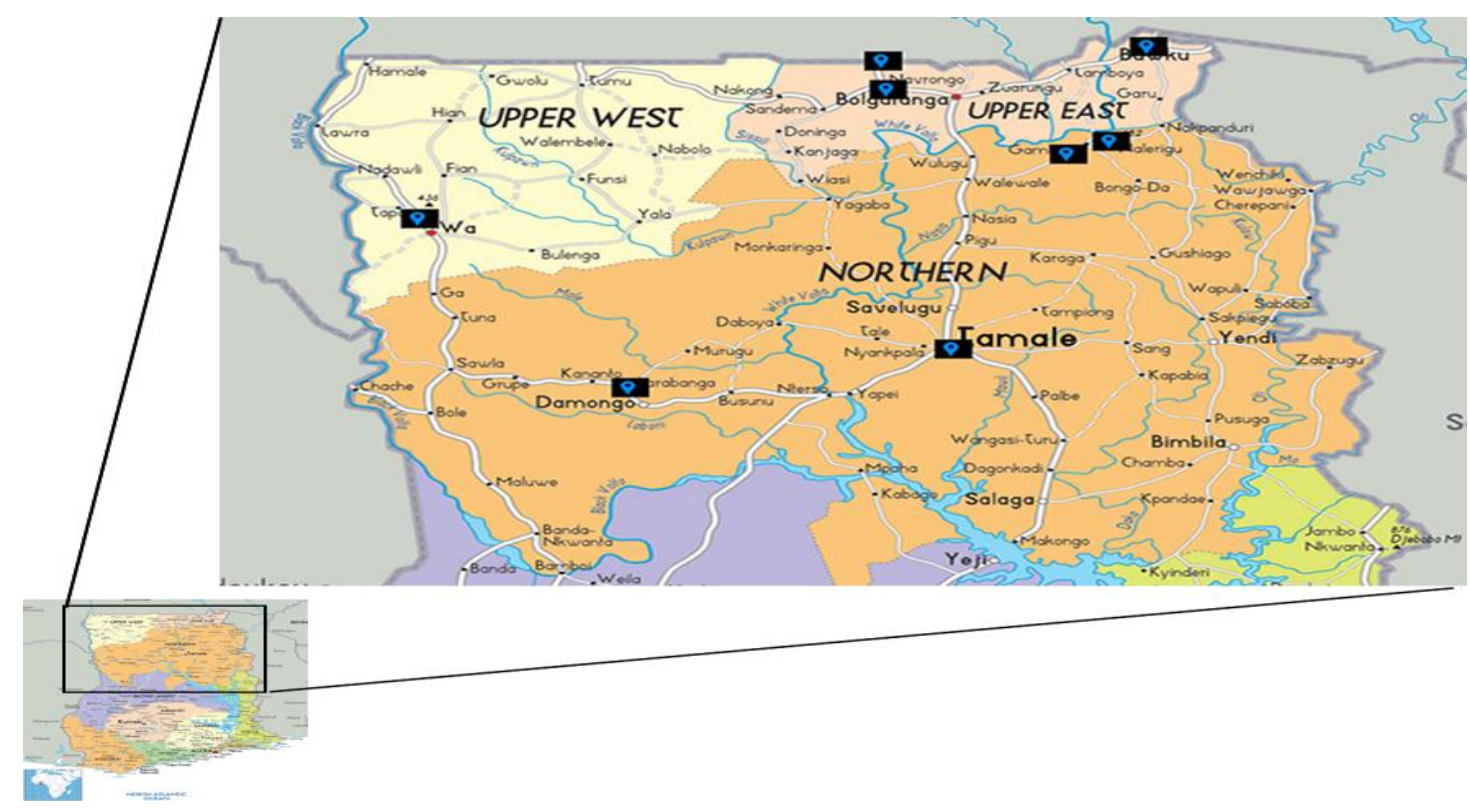

Figure 2: Map of Northern Ghana showing data collection sites

\subsection{Recent developments in Mobile Money}

With a total amount of GHS35.4billion passing through mobile money in 2015 alone [17], the significance of mobile money was beginning to become clear. The Bank of Ghana hence in July 2015 decided to streamline the developments by introducing regulations. Thus, since 2015 the mobile money departments of telecom companies were decoupled from the bigger company. Thus, for example, Tigo Cash, the then mobile money department of the Tigo network became an independent and separate entity from the network. Such a development is seen to present numerous opportunities including a better partnership between mobile money services and traditional banking institutions. There has been an almost immediate impact on the sector, which has driven competition leading to more innovations. The total amount of mobile money transacted in 2015 by the four mobile money service providers represents $85.8 \%$ of the total deposit liabilities of the 29 banks as at the end of 2015 , a figure that is likely to be surpassed by the mobile operators by of end 2016 .

\subsection{Recent Developments in Mobile Money Service}

\section{i. The Jara account}

Stepping up the competition even further, Airtel Money launched the Airtel Jara Account in November 2015. For the first time, mobile money users would earn interest on the money saved in their mobile wallets. As of the time of writing this paper, it is too early to evaluate the impact, but we posit that this might elicit a more positive PU of the service and thus a more positive ATU. MTN responded to this in second quarter 2016 by launching a competitor product announcing, it would soon offer interest on mobile money accounts. All these developments are expected to contribute to the reshaping of the mobile money sector.

\section{ii. Mobile Money Loans}

In May 2016, Airtel and Tigo almost simultaneously began running adverts promoting their latest Mobile Money products - Mobile Money Loans.

Airtel called its loan scheme the Airtel Money Bosea allowing customers to get instant loans of up to GHC 200 with a one month to pay back period through deductions via their Airtel Money wallets [18].

MTN Mobile Money's product is dubbed the Mjara loans and like the Airtel Money Bosea, it offers short term loans with payment periods between two and three weeks [19].

Both products are in conjunction with established financial institutions - Airtel partners Fidelity Bank whiles MTN partners MFS Ghana

It is expected that innovations will grow across the sector leading to a continuous convergence between mobile money and traditional banking. The research believes these new developments will translate into an upward perception of usefulness (PU) and thus a more positive Attitude Towards Use (ATU).

i. International Mobile Money Transfer

Although not a 'recent' development, the market leader's MTN Mobile Money has become the fastest growing method of receiving international money transfers in Ghana [20]. Recently growing at $13 \%$ per month, this method of receiving money from US, Canada and Australia now allows senders outside of the country to send small amounts at a higher frequency to friends and relatives in Ghana to help settle bills and other obligations.

\section{ii. Bank of Ghana Directive for E-Money service} providers to pay interest

As described in this document, some mobile money service providers have already taken the initiative to reward customers with interests on their 'mobile savings'. The Bank of Ghana has, however, since July 2016, in its Guidelines For E-Money Issuers In Ghana, directed that mobile money account holder be paid interest on the account. Specifically, "E-money issuers shall pass-through not less than $80 \%$ of the interest accrued on the pooled e-money float net of any fees or charges related to the administration of the pooled float accounts to e-money holders" [21]. In the second and third quarter of 2016, the bank sought to enforce this directive. Hence, with retrospective effect, all mobile money account holders would earn interest from January 2016. 


\section{DISCUSSIONS}

The discussions around the findings of the research linger around;

- What are the perceptions of ease of use current mobile money users?

- What are the perceptions of usefulness of the service?

- What are the attitudes towards use of the service?

- Current developments

\subsection{Perceptions of ease of use}

To measure this, a likert scale and the question, "How difficult is it to use Mobile Money?" were used. Respondents mostly agreed that using mobile money was largely an easy process. More than 2 in every 3 respondents (68\%) indicated that the mobile money service was "Very Easy" to use. The positive responses are particularly stronger with users who have been using the service for longer periods. [22] Assert that users of new technologies tend to have more positive perceptions with repeated usage - Experience.

\subsection{How difficult is it to use Mobile Money?}

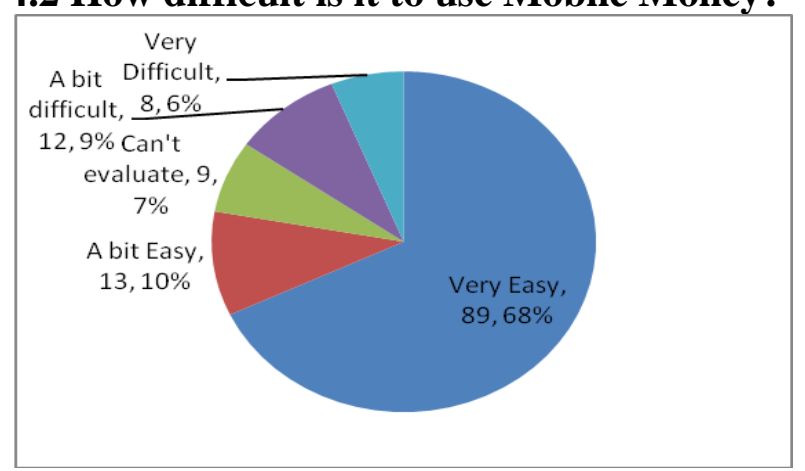

Figure 3: Perception of Ease of Use of Mobile Money

The reported ease is despite the reported challenges of frequent "Network Failure" mentioned by $74 \%$ or respondents, "Lack of cash at agent" faced by $47.3 \%$ and complaints of service charges being "too high" $33.59 \%$.

\subsection{Perceptions of usefulness}

Since mobile money is mainly about keeping money in an electronic format (usefulness), the research decided to formulate the following question to point to perceived usefulness; "How do you feel about your finances since you started to use mobile money?"

Table 1: Common Uses of Mobile Money Service

\begin{tabular}{|l|l|l|}
\hline Service & Frequency & $\begin{array}{l}\text { Percentage } \\
\text { Usage }\end{array}$ \\
\hline Withdraw Money & 102 & $77.9 \%$ \\
\hline Save Money & 87 & $67.4 \%$ \\
\hline Transfer Money & 83 & $63.4 \%$ \\
\hline Topping up phone credit & 57 & $43.5 \%$ \\
\hline Payment of bills & 9 & $6.9 \%$ \\
\hline Payment of fees & 3 & $2.3 \%$ \\
\hline Receiving Salary & 3 & $2.3 \%$ \\
\hline Payment of Salary & 1 & $0.8 \%$ \\
\hline
\end{tabular}

In the first place, mobile money users have found or perceived the service to be useful and that is why they opted for the service. With the fast paced growth of mobile money service subscribers, the takes this as a pointer to generally positive perception of usefulness of the product. As shown in Table 1, the research opted to zoom in specific mobile services to test perception of their usefulness and thus adoption. Nearly four in every five respondents (77.9\%) mentioned the receipt of money (Withdraw Money) as a service they patronize within the bouquet of services provided by mobile money range of services. It is worth mentioning that the research focused on mobile money users located in low income earning communities (rural communities) thus this coincides with the fact that migrants to bigger cities [and countries] also take responsibility for the financial needs of family and friends in rural areas. They frequently remit monies back home [23]; [24]; [25]. It was not statistically prudent to directly compare the results of this variable between big city and rural community dwellers as it turned out that majority of the city dwellers, $65 \%$, who completed the questionnaire were students and who were likely to be dependents and thus likely to be more on the receiving end of money transfer. A smaller, yet statistically significant, percentage $63.4 \%$ mentioned sending money (Cash out) as a service they have patronized in the past. We found that nearly 1 in $10(7.6 \%)$ mobile money users have never sent money out although some of them have been on the service for at up to five years and have received money through the platform on multiple occasions.

Using mobile money for the "Payment of bills", "Payment of fees", "Receiving Salary" and "Payment of Salary" were not very popular with respondents with each scoring recording less than 7\% usage level amongst the sample size of 131 respondents. The research notes that these are services that individual users cannot take advantage of without the initiative of corporate bodies.

\subsection{Attitudes towards use of Mobile Money Service}

Relying on the Technology Acceptance Model and the deduced diagramme in Fig 1 and based on the findings of the research on PEOU and PU, the research concludes that mobile money users generally have a positive attitude towards the use of the Mobile Money Service.

\subsection{As a competitor to traditional banking}

Less than 1 in 3 Ghanaians operates a bank account. As pointed out earlier, just about $30 \%$ of residents in Ghana are banked. Although still bigger than the $17 \%$ mobile money penetration, traditional bank accounts are not increasing in number as much as mobile money wallets. As forecasted by the Business and Financial Times, by close of 2016, mobile money transactions would have overtaken the total bank deposits in Ghana. However, some more analysis is required to be able to draw a conclusion as to whether or not mobile money will compete with traditional banking. A critical point of note is that mobile money is largely remittance driven. It may, for example, be rhetorical at the present to postulate that a multimillion Ghana cedi gold mining firm will operate its entire account from a mobile money account. Neither is it safe for now to assume a time will come when a university will receive all school fees from students via mobile money. To obtain a clearer picture of the comparative flow of money through mobile wallets and bank accounts, the research suggested discrete amounts of money in Ghana Cedis; ranging from 50 to $2500+$ and asked whether they would save such an amount of money in their mobile wallets or in a traditional bank account over specified periods; 2 weeks, 1 month, 2 months, 12 months and over 12 months. The results are summarised in table 2 below 
Table 2: Preference for Mobile Money and Bank Accounts for Saving Money

\begin{tabular}{|l|l|l|l|l|l|l|}
\hline $\begin{array}{l}\text { Amount } \\
\text { (GHS) }\end{array}$ & Mode & $\begin{array}{l}\text { Up } \\
\text { to 2 } \\
\text { wks }\end{array}$ & $1 \mathrm{mth}$ & $\begin{array}{l}2 \\
\text { mnths }\end{array}$ & $\begin{array}{l}\text { Up to } \\
12 \mathrm{mnths}\end{array}$ & $\begin{array}{l}\text { Over } \\
12 \\
\text { mnths }\end{array}$ \\
\hline \multirow{2}{*}{$2500+$} & Bank & 82 & 85 & 87 & 84 & 86 \\
\cline { 2 - 7 } & MW & 20 & 15 & 14 & 15 & 14 \\
\hline \multirow{3}{*}{1500} & Bank & 76 & 83 & 84 & 84 & 85 \\
\cline { 2 - 7 } & MW & 28 & 17 & 16 & 14 & 16 \\
\hline \multirow{3}{*}{500} & Bank & 74 & 82 & 80 & 81 & 85 \\
\cline { 2 - 7 } & MW & 30 & 20 & 20 & 17 & 14 \\
\hline \multirow{3}{*}{350} & Bank & 63 & 65 & 61 & 73 & 76 \\
\cline { 2 - 7 } & MW & 43 & 36 & 35 & 24 & 22 \\
\hline \multirow{2}{*}{250} & Bank & 40 & 42 & 56 & 64 & 71 \\
\cline { 2 - 7 } & MW & 63 & 58 & 45 & 37 & 28 \\
\hline \multirow{2}{*}{50} & Bank & 28 & 26 & 41 & 55 & 64 \\
\cline { 2 - 7 } & MW & 83 & 77 & 57 & 46 & 39 \\
\cline { 2 - 7 } & Bank & 14 & 17 & 24 & 43 & 53 \\
\hline
\end{tabular}

MW $=$ Mobile Wallet, Bank $=$ Traditional Bank Account

The shaded portions of the table show where respondents preferring mobile money as a savings option outnumber the reverse. The summary indication is that users will prefer to save relatively smaller amounts of monies for shorter periods in their mobile wallets. Larger amounts over longer periods are more likely to be deposited in bank accounts.

To this end, in the current form, mobile money is not a threat to traditional banking.

It is foreseeable that the number of individual users will continue to increase for a while longer and thus the volume of money transacted across mobile money platforms. A grey area of interest still remains however - "As income levels increase, are individuals more likely to increase the amount of money they save in their mobile wallets?"

The captured data included income levels of respondents. Income levels are analysed against how much money respondents are willing to put away in their mobile money wallets.

\section{Regression Analysis}

Table 3: Model Summary

\begin{tabular}{|l|l|l|l|l|}
\hline & & R & Adjusted & $\begin{array}{l}\text { Std. Error } \\
\text { of the } \\
\text { Model }\end{array}$ \\
\hline 1 & R & Square & R Square & Estimate \\
\hline
\end{tabular}

\section{Statistical Significance}

Table 4: ANOVA ${ }^{b}$

\begin{tabular}{|ll|l|l|l|l|l|}
\hline Model & & $\begin{array}{l}\text { Sum of } \\
\text { Squares }\end{array}$ & df & $\begin{array}{l}\text { Mean } \\
\text { Square }\end{array}$ & F & Sig. \\
\hline 1 & $\begin{array}{l}\text { Regressi } \\
\text { on } \\
\end{array}$ & 239.856 & 35 & 6.853 & 1.171 & $.270^{\mathrm{a}}$ \\
& $\begin{array}{l}\text { Residual } \\
\text { Total }\end{array}$ & 795.991 & 95 & 5.853 & & \\
& 795.847 & 130 & & & \\
\hline
\end{tabular}

a. Predictors: (Constant), Over 2500 cedis for more than a year, 350 cedis for 1 or 2 weeks, 50 cedis for 1 month, 250 cedis for more than a year, 350 cedis for 2 months, 2500 cedis for 1 or 2 weeks, 50 cedis for 1 or 2 weeks, 500 cedis for 1 month, 250 cedis for 1 or 2 weeks, Over 2500 cedis for 1 month, 500 cedis for more than a year, 500 cedis for 1 or 2 weeks, 50 cedis for 3-12 months, 2500 cedis for more than a year, 250 cedis for 2 months, 1500 cedis for 2 months, 1500 cedis for 1 or 2 weeks, 250 cedis for 3-12 months, 350 cedis for 1 month, 350 cedis for more than a year, 500 cedis for 2 months, 50 cedis for 2 months, Over 2500 cedis for 1 month, 250 cedis for 1 month, 500 cedis for 3 - 12 months, 2500 cedis for 1 month, 50 cedis for more than a year, Over 2500 cedis for 3 - 12 months, 2500 cedis for 2 months, 1500 cedis for 1 month, 350 cedis for 3 - 12 months, 2500 cedis for 3 - 12 months, Over 2500 cedis for 2 months, 1500 cedis for more than a year, 1500 cedis for $3-12$ months

b. Dependent Variable: What is your average income per month (in GHS)?

The Model Summary (Table 3) and ANOVA (Table 4) use the same predictors and data set.

The F-ratio in the ANOVA table in Table 4 sought to test whether the overall regression model is a good fit for the data. The output showed that the independent variables (amount of money respondents are willing to save in either mobile money wallet or bank account for specific times)was not statistically significantly related to or predict the dependent variable (monthly income), $\mathrm{F}(35,95)=1.171, \mathrm{p}<.0005$

The amount of money people are willing to 'put away' in their mobile wallet is independent of their income levels.

Having established that mobile money is not, at the present, a threat to traditional banking, the research sought to find out if there are any potential factors capable of changing the status quo.

What will make mobile banking become a threat to traditional banking? The research sought to answer this by studying the disincentives to the use of mobile money

Table 5: Descriptive Statistics

\begin{tabular}{|l|l|l|}
\hline & N & Sum \\
\hline Not applicable & 131 & 8.00 \\
Network Failure & 131 & 97.00 \\
Lack of cash at the agent & 131 & 62.00 \\
Service Charges Too High & 131 & 44.00 \\
Mobile money agent is far from & 131 & 12.00 \\
where I live & 131 & .00 \\
Other & 131 & \\
Valid N (listwise) & \\
\hline
\end{tabular}

In a multi-select question, only $8(6 \%)$ of respondents reportedly had no problem at all using mobile money. The commonest complaint was the intermittent 'Network Failure' alluded by 97 (74\% of) respondents. The next commonest complaint was the 'Lack of cash at the agent'; 62 (47\%).

The research observed that mobile money agents are usually small sized entrepreneurs who trade using their own money. The telecom companies for whom they trade for, pay them commissions based on their volumes of transactions. It is therefore possible that a client may not be able to access large amounts of money deposited into his mobile wallet because the mobile money agent does not have that amount of disposable cash. 
Network failure and the lack of cash may be the main challenges found in the survey. The interview revealed other challenges.

"Why should I save money in my wallet for a long time when I earn no interest on it? And yet, they take a commission when I go to withdraw my own money" (Jessica Azantilow, 26, student)

This was before the introduction of the interest earning regimes of Airtel Money and MTN Mobile Money; an indication that the adoption of interest earning options across the board might lead to a better acceptance of mobile money as a service.

The challenge of "Network Failure" is not peculiar to the mobile money agents. Traditional banks do face this problem as well. [26] points out despite years of massive investments by banking institutions in Information Systems infrastructure, they acknowledge recurring technical challenges including when 'the network is down'.

The advantage, however, of traditional banks over mobile money service is that banks do offer a higher guarantee of access to funds within working hours. Mobile money offers convenience. Thus, to push further the boundaries of mobile money usage, providers will have to explore further, how to ensure the availability of cash at the level of the agent.

\section{The Impact of New Developments}

The lines of distinction between mobile money accounts and traditional bank accounts are blurring with the changes in service and scope accompanying each, and recent, innovations by mobile money issuers. The new interest earning features make it more attractive for account holders to leave moneys in their mobile wallets for longer periods and attend to the worries of Jessica quoted in this research.

Further increasing the attractiveness of mobile money is the ability of users to access loans. The interest rates on mobile money loans are still very high, for example MTN charges $4 \%$ for between 2 and 3 weeks of loan; this works out to between 42 and 56\% interest per annum. The research anticipates that this will improve with time and competition. It at least gives users access to one more service that traditional banks offer.

These developments mean, e-money, or mobile money is gradually inching into area known to be occupied by traditional banking - it could become a threat.

Mobile money may, however, be more complementary that substitute for traditional banking. E-money issuers are not banks and therefore do not have facilities to hold money. What they may do actually is to mop up hard cash and convert same to electronic money. They in effect will increase the amount of banked money and invariably the number of banked Ghanaians. Thus, if there is proper coordination, mobile money issuers may actually just become 'branches' of traditional banks helping reach out especially to the unbanked population

\subsection{Mobile Money as convenience}

Travelling in search of data for the research, the research team found only one bank between Walewale and Garu, the Bangmarigu Rural Bank. This is a distance of 111 kilometers with at least 25 inhabited towns and villages. For interviewees along this route, the over a dozen visible mobile money agents provide a welcome relief. Fusheina, a 22 year old teacher who also doubles as a mobile money agent adds;
"For most traders in Nalerigu, instead in travelling to Gambaga or Walewale to put money in the bank, they can just save it in their mobile wallets, travel to where they buy their goods and through mobile money withdraw their monies and do their trade safely"

\subsection{Summary of findings}

- Mobile Money is more complementary than substitutive to traditional banking

- Respondents generally perceive mobile money as an easy to use service although the platform has technical challenges

- The attitude towards mobile money use is generally positive

- Mobile money is popular mainly for its convenience

- Mobile money is predominantly used for remittances and safe keeping of money

\subsection{Recommendations}

- Service providers should place more emphasis on the use of mobile money for the payment of goods and services. Any efforts at getting more users to use the service for the payment of bills, fees, salaries etc will likely increase the frequency of use of the service.

- The payment of interest and allowance for loans should be developed further to further deepen the financial interaction between mobile money users and service providers

\section{REFERENCES}

[1] Beattie, A., (2016). The History Of Money: From Barter To Banknotes. Investopedia. Online http://www.investopedia.com/articles/07/roots_of_mone y.asp

[2] Headrick, D. R. (2009). Technology: a world history (pp 54-56). New York: Oxford University Press.

[3] Moshenskyi, S. (2008). History of the Weksel. New York: Xlibris

[4] Hogendorn, J., \& Johnson, M. (2003). The Shell Money Of The Slave Trade(Vol. 49). Cambridge University Press.

[5] Osei, A. M., Seth, A., \& John, A. (2015). Customers'preference In Service Delivery, An Assessment Of Tam And Idt On The Means-End Theory In The Banking Industry: A Case Of Ghana Commercial Bank Ltd In Ghana. European Journal Of Business And Social Sciences, 3(11), 79-100.

[6] Abor, Joshua. Technological innovations and banking in Ghana: An evaluation of customers' perceptions, American Academy of Financial Management 1 (2004): $1-16$

[7] Osiakwan, E., (2003). Ghana's Teledensity Report, Ghanaweb, Accra

[8] National Communications Authority, (2008). Annual Report 2008, Retrieved from NCA website: http://nca.org.gh/downloads/NCA_Annual_Report_2008. pdf 
[9] National Communications Authority, (2016). Industry Information - Telecom Subscriptions For February 2016, Retrieved from NCA website: http://www.nca.org.gh/downloads/Telecom_subscription _trends_for_February_2016.pdf

[10] Hollow, M., (2012). Pre-1900 utopian visions of the 'cashless society', Munich Personal RePEc Archive, Online at https://mpra.ub.uni-muenchen.de/40780/

[11] Telecoms Chamber Communications Desk, (2016, January 22). Mobile Money Usage Doubles in 12 Months. Retrieved from: http://telecomschamber.org/mobile-money-usagedoubles-in-12months/

[12] F. D. Davis (1989), Perceived usefulness, perceived ease of use and user acceptance of information technology, MIS Quarterly, Vol. 13 (3), pp. 319-340

[13] Chen, J. V., \& Aritejo, B. A. (2008). Service quality and customer satisfaction measurement of mobile valueadded services: a conceptual review. International Journal of Mobile Communications, 6(2), 165-176

[14] Carlsson, B. (2006). Internationalization of innovation systems: A survey of the literature. Research policy, 35(1), 56-67

[15] Ho Cheong, J., \& Park, M. C. (2005). Mobile internet acceptance in Korea. Internet research, 15(2), 125-140

[16] Ndanu, M. C., \& Syombua, M. J. (2015). Mixed Methods Research: The Hidden Cracks of the Triangulation. Name: General Education Journal, 4(2)

[17] Abbey, R. A., (2016, May 17).Mobile money transactions hit GHS35.4bn. Business and Financial

[18] CitiFMOnline. (Ed.). (2016, May 11). Airtel launches first mobile based lending scheme. Retrieved May 15, 2016, from http://citifmonline.com/
[19] Graphic online, http://www.graphic.com.gh/business/business-news/mtnlaunches-new-mobile-money-product.html

[20] Ghanaian diaspora embrace MTN Mobile Money sending with WorldRemit. (2016). Ghanaweb.com. Retrieved 15 June 2016, from http://www.ghanaweb.com/GhanaHomePage/NewsArchi ve/Ghanaian-diaspora-embrace-MTN-Mobile-Moneysending-with-WorldRemit439737? promoted=worldRemit

[21] Times Online. Retrieved from: http://thebftonline.com/business/economy/18970/mobilemoney-transactions-hit-gh354bn.html\#

[22] V. Venkatesh, M. G. Morris, G. B. Davis and F. D. Davis (2003), User acceptance of information technology: toward a unified view, MIS Quarterly, Vol. 27, pp. 425478

[23] Awumbila, M., Teye, J. K., \& Yaro, J. A. (2016). Social Networks, Migration Trajectories and Livelihood Strategies of Migrant Domestic and Construction Workers in Accra, Ghana. Journal of Asian and African Studies, 0021909616634743

[24] Awumbila, M., Owusu, G., \& Teye, J. K. (2014). Can rural-urban migration into slums reduce poverty? Evidence from Ghana. Migrating Out of Poverty Working Paper, 13, 1-41

[25] Rempel, H., \& Lobdell, R. A. (1978). The role of urban-to-rural remittances in rural development. The Journal of Development Studies, 14(3), 324-341

[26] Ankrah, E. (2015). The Impact of Information Systems Investment on Bank Performance in Ghana. Advances in Social Sciences Research Journal, 2(11) 